\title{
Disabled in Society - A Scoping Review on Persons Living with Multiple Sclerosis and Disability
}

\author{
Daniel Ståhl $\mathbb{D}^{\prime}$, Ylva Bjereld $\mathbb{D}^{1,2}$, Anna Dunér $\mathbb{D}^{\prime}$ \\ 'Department of Social Work, University of Gothenburg, Gothenburg, Sweden; ${ }^{2}$ Department of Behavioural Sciences and Learning, Linköping \\ University, Linköping, Sweden
}

Correspondence: Daniel Ståhl, Department of Social Work, University of Gothenburg, Sprängkullsgatan 23, PO Box 720, Gothenburg, SE 405 30, Sweden, Tel +46766 186 878, Fax +46 31786 1888, Email daniel.stahl@gu.se

\begin{abstract}
Multiple sclerosis (MS) is a chronic neurological disease with an increasing prevalence. As such, most studies are devoted to various medical aspects of the disease. The theoretical framework used in this scoping review was the social model of disability a perspective focusing on environmental barriers and discrimination that disabled people face in society. The aim was to explore previous research on disabling barriers and discrimination against persons with MS, and to identify research gaps in connection with this population. The scoping review was performed in two steps: (1) a main search in 8 databases, followed by (2) citation and reference searches. The final sample consisted of 96 included articles. The result showed that most studies had been conducted in the US, and the dominant area of research was employment discrimination. Previous research has studied MS related to various areas, such as employment, social welfare and social services, transportation, housing and accessibility of public places, health services, and in relation to others within society. However, this scoping review showed that although several areas of disability and MS had been included in the previous research, most of the identified areas were researched in few studies without the possibility to generalize the findings to a larger population or a cross-cultural context. Few studies compared differences between persons with MS based on gender, age, and ethnicity. What impact the invisible symptoms of MS had on disability was also researched to a limited extent. The findings have implications for future research and clinical practice. To better understand living conditions for persons with MS from a global perspective, more research across countries is needed. Healthcare professionals need to assess the individual's situation regarding both symptoms of the disease and the impact of societal barriers and discrimination to optimize care of persons with MS. Keywords: multiple sclerosis, disability, disabled people, the social model of disability, discrimination, barriers
\end{abstract}

\section{Introduction}

In 2006, the Convention on the Rights of Persons with Disabilities and its Optional Protocol was adopted by the United Nations. The convention was intended to change the view of disabled people from passive objects who were best treated by experts to active subjects who have rights and a will, just like other humans. A central part of this convention is that disabled people should have the right to be active members of society. The convention recognizes barriers in society, which hinder disabled people from full participation. ${ }^{1}$ Multiple sclerosis (MS) is a chronic neurological disease that in 2020 was estimated to affect 2.8 million people worldwide. ${ }^{2}$ The global prevalence has continued to increase when comparing the estimates for 2008, which was 2.1 million people, and 2013, which was 2.3 million people. ${ }^{2,3}$ Contributing factors that presumably explain the rising prevalence of MS are developed diagnostic criteria and neuroimaging, improved registers and counting methods, and better treatment and survival rates of persons with MS. ${ }^{2,4}$ MS is estimated to be the most common non-traumatic neurological cause of impairment for younger adults. ${ }^{5}$ Most persons diagnosed with MS are between 20 and 40 years old, ${ }^{5,6}$ an age span where many enter the labor market, start a family, and invest in education. As a medical diagnosis, many studies on MS are devoted to treatment management and assessments of the individual's capacities. In this scoping review, the framework of the social model of disability is used. By utilizing this model, the gaze is directed at the barriers and discrimination that disabled people face in society. In other words, the social model of disability is about equal rights in society for all people. ${ }^{7}$ 
Disability is a commonly used term for persons with various diseases or injuries. It is imperative to note that the concept is used with different intentions. In medical research, disability is usually used to describe the deterioration of a person's function because of a disease, see, for example. ${ }^{5,8,9}$ In some cases, the concepts of disability and impairment are used synonymously, see, for example. ${ }^{5,9}$ By using the social model of disability's framework, the concepts impairment and disability are separated. Impairment is used to describe deterioration in bodily function related to the body and/ or the mind. Impairment can be the result of disease or injury, or can be congenital. ${ }^{7,10}$ Disability, on the other hand, is used to describe barriers and discrimination against disabled people in relation to society. ${ }^{7,10,11}$ In other words, disability according to the definition used - is about social injustice facing disabled people. Henceforth, when referring to the concepts of disability and impairment, they are used as described according to the social model of disability unless otherwise noted.

The aim of this scoping review was to explore previous research on disabling barriers and discrimination against persons with MS, and to identify research gaps in connection with this population.

\section{Background}

\section{Multiple Sclerosis}

MS is a chronic neurological disease of the central nervous system that cannot be cured. However, a variety of therapies have been available since the $1990 \mathrm{~s} .{ }^{8}$ Early treatment of MS will, in many cases, delay the progression of impairment. ${ }^{6}$ The disease is approximately twice as common among women than men. ${ }^{5,6} \mathrm{MS}$ is more common in Northern Europe and North America than in the rest of the world. Many studies are devoted to MS because of its prevalence and consequences, but the causes are still unknown. The disease is heterogenous in its manifestations, and various subtypes exist. MS may involve symptoms such as: impaired vision and eye function, sensory symptoms, impaired motor function, sexual dysfunction, impaired bladder function, fatigue, cognitive impairment, and depression. ${ }^{5}$

As a neurological diagnosis, the research tends to concentrate on medical aspects of the disease. Social aspects are not unexamined in the previous research, but focus mostly on standardized measurements, such as QoL (Quality of Life), ${ }^{12-14}$ mental and emotional aspects of the disease, ${ }^{15,16}$ social support, ${ }^{12,13,15}$ or the economic costs of MS. ${ }^{17}$ Some aspects of disability are highlighted in studies, for example, independence in mobility, ${ }^{13,18}$ social exclusion, and environmental barriers. ${ }^{13}$ However, these systematic reviews were directed at topics other than disabling barriers and discrimination in society.

\section{Clinical Relevance}

As time passes since a person is diagnosed with MS, impairment will eventually debut and increase. ${ }^{6,19}$ A longitudinal study found that over a 10-year period, many persons with MS's capacity to participate in activities and society decreased. ${ }^{19}$ Although there is no cure for MS, studies have showed positive outcomes in the social participation of persons with MS attending multidisciplinary rehabilitation. ${ }^{20,21}$ This scoping review seeks to contribute to clinical practice by highlighting the societal barriers and discrimination that persons with MS face.

\section{Methodology \\ Study Design}

This scoping review was primarily based on the guidelines of Arksey and O'Malley ${ }^{22}$ and the later work by Levac, Colquhoun, and O'Brien. ${ }^{23}$ The PRISMA-ScR Checklist was used for guidance. ${ }^{24}$ A scoping review was chosen because such a design allows research to be examined from different fields, as well as identifying possible research gaps without assessing the quality of included studies. ${ }^{22}$ During the research process, a team approach was followed. ${ }^{23,25}$ The research team discussed and decided together on the research question, the keywords for searches, and the inclusion/exclusion criteria, and worked together in the process of study selection.

\section{Search Process and Study Selection}

The search process was conducted in two steps: (1) a main search, henceforth referred to as the scoping search, followed by (2) citation and reference searches. The scoping search strategy included databases beyond the social sciences to 
establish that relevant research on disability from multiple fields was included. The selected databases were ASSIA (Applied Social Sciences Index and Abstracts), CINAHL (Cumulative Index for Nursing and Allied Health Literature), PsycInfo, Social Services Abstracts, Sociological Abstracts and Sociology Database, Scopus, and Web of Science. The search terms were derived from the established literature on disability according to the social model.

To identify previous research on disabling barriers and discrimination against persons with MS the following inclusion criteria were used in the scoping review: empirical peer-reviewed original articles in English, with a complete or partial focus on adult (aged 18 or over) persons with MS and disability according to the social model (eg disabling barriers and discrimination), published in 2000 until the inception of 2021. A full description of the search terms is available in Appendix 1.

Articles were excluded if they presented results on disability that concerned both persons with MS and persons with other diseases, without presenting separate results report for each group. Articles that had a plausible disability-related topic (eg employment and independent living) that presented the problem in terms of individual deficiency were excluded. Finally, studies that only presented the results as individual quotations from adult persons with MS on disability topics were excluded as the quotations without any further analysis were not considered as results.

The first author conducted the scoping search between December 18, 2020 and February 4, 2021. This process included the initial screening by reading the article titles and abstracts, using EndNote X9. If articles could not be excluded, they were saved for later full-text reading $(\mathrm{n}=309)$. See Figure 1 for a summary of the study selection process. Duplicates $(n=87)$ were removed. The saved articles $(n=222)$ were read in full by the first and third authors, specifically examining the results section. In the next step, the first and third authors discussed their assessments. In every case where inclusion or exclusion was unanimously assessed, the article was included or excluded. In the case of disagreement $(n=34)$, the article was read by the second author who made the definite decision in line with a team approach. ${ }^{23}$ In total, 84 articles were included after the scoping search. One article, Khan, Amatya, and $\mathrm{Ng}^{26}{ }^{26}$ was excluded because the data for persons with MS were already present in another included article. This later article compared the data for persons with MS to persons with another disease, which was outside the scope of this study.

The scoping search and study selection process were followed by citation and reference searches conducted by the first author. The reference lists of the included $(n=84)$ articles were reviewed, and citation searches were performed on these articles in Scopus. ${ }^{22}$ This process was carried out between April 6 and April 9, 2021. Article titles were read, and if an article could not be excluded by title, the abstract was read. After this step, 26 articles were saved for full-text reading. The first and second authors conducted the full-text review. In this process, the authors disagreed with the assessment in four of the cases. These articles were then discussed between the first and second authors. In one case, inclusion was decided on. Twelve articles were included in this segment. In total, 96 articles were included.

\section{Data Analysis}

Data was charted in Microsoft Excel according to a descriptive analytical method. ${ }^{22}$ Charting categories were derived from the recommendations of Arksey and O'Malley, ${ }^{22}$ and additional categories were added after discussion in the research team. ${ }^{23}$ Studies were classified regarding their disability foci, which could be one or more areas, for example, employment, transportation, or health services.

\section{Results}

\section{Descriptive Findings}

Ninety-six articles were included in this scoping review. The majority of the included studies were conducted in the US $(\mathrm{n}=46)$. As shown in Table 1, there was a gap down to the second and third most frequent countries, Australia $(\mathrm{n}=14)$ and the UK $(n=10)$. Other than North America, Europe, and Australia, only three countries were represented from other continents: Iran $(\mathrm{n}=5)$, Malaysia $(\mathrm{n}=2)$, and Jordan $(\mathrm{n}=1)$. Considering the year of publication, no year differed drastically in terms of published articles. The initial years of the 21 st century accounted for only a few included publications. The numbers have since increased with every five-year period, with the highest number of included articles published between 2015 and $2019(\mathrm{n}=34)$. Over 90\% $(\mathrm{n}=87)$ of the included studies included both female and male 


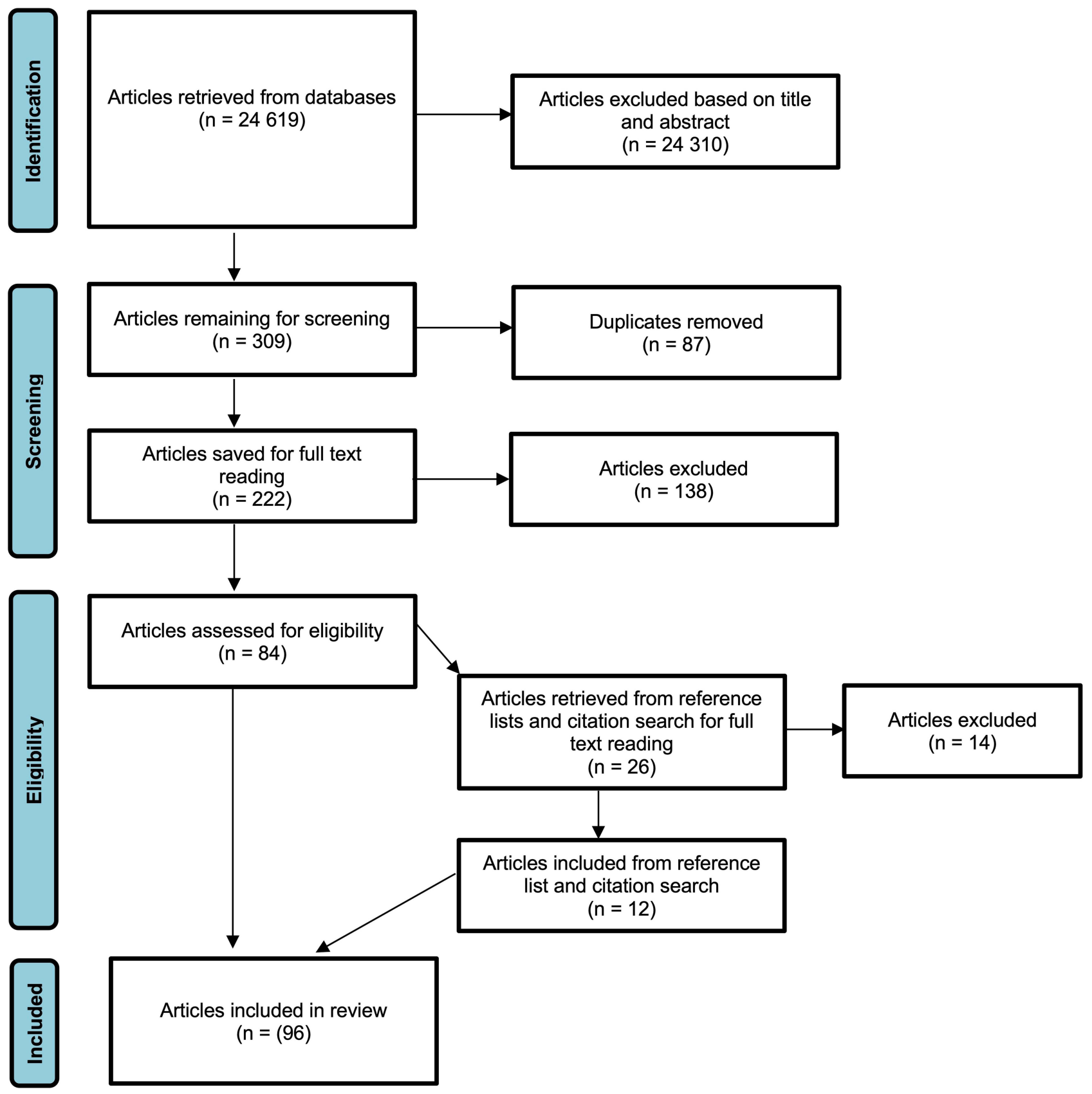

Figure I PRISMA flow chart of the study selection process. PRISMA flow chart, visualizing the process of inclusion and exclusion of studies divided into four steps: identification of studies, screening of studies, eligibility assessment, and included studies.

Notes: Adapted from: Tricco AC, Lillie E, Zarin W, et al. PRISMA extension for scoping reviews (PRISMA-ScR): checklist and explanation. Annals of internal medicine. 2018;169(7):467-473. ${ }^{24}$ Creative Commons.

persons with MS. More than half of the studies $(n=58)$ were devoted to employment. Social welfare and social services constituted the second most commonly occurring subject $(n=26)$. Articles that address transportation were the third most frequent disability topic $(\mathrm{n}=20)$. The majority of the included studies used quantitative methods $(\mathrm{n}=53)$. Included articles were derived from a variety of scientific fields. Rehabilitation $(n=36)$ and medicine $(n=12)$ were the most common fields of science, together with articles classified as interdisciplinary $(\mathrm{n}=12)$. Interdisciplinary articles were authored by scholars from both natural sciences and social science fields, see, for example. ${ }^{27-29}$ Traditional social sciences constituted seven articles in total: social work $(n=2)$, sociology $(n=1)$, and psychology $(n=4)$. 
Table I Descriptive Findings from the Included Articles - Top 3

\begin{tabular}{|l|l|}
\hline Descriptive & Top 3 \\
\hline National source & $\begin{array}{l}\text { US }(n=46) \\
\text { Australia }(n=14) \\
\text { UK }(n=10)\end{array}$ \\
\hline Number of articles by five-year period & $\begin{array}{l}2015-2019(n=34) \\
20 I 0-20 I 4(n=24) \\
2005-2009(n=18)\end{array}$ \\
\hline Population & $\begin{array}{l}\text { Persons with MS }(n=71) \\
\text { Allegations from persons with MS ( } n=6)\end{array}$ \\
Persons with MS and persons with another disease $(s)(n=5)$ \\
Persons with MS, their relatives, and professionals $(n=5)$
\end{tabular}

Many articles had a focus on a certain topic, such as employment discrimination. It was also common for articles to touch upon several areas where disability occurs and, for that reason, some articles were included in more than one category. The following categories were charted from the data: employment, social welfare and social services, transportation, home/public place accessibility, health services, and negative attitudes from others. The distribution of charted categories and examples of key results are presented in Table 2.

\section{Employment}

Fifty-eight studies were devoted to employment, either solely or partially. Of these employment-related studies, more than half $(\mathrm{n}=30)$ were from the US. Persons with MS were in employment to a lesser extent than persons without impairment in Australia. ${ }^{30}$ In a large American survey, less than $40 \%$ of the respondents were employed. ${ }^{31}$ However, one Australian study contradicted previous results. It was shown that the gap in employment rates between persons with MS and the general population was reduced between 2010 and 2013 in Australia. ${ }^{32}$ The situation regarding employment for persons with MS has been negatively affected by the Covid-19 pandemic. Almost 30\% of respondents with MS in a smaller survey reported work loss as a direct consequence of the pandemic. However, the study did not compare persons with MS to the general population. ${ }^{33}$

Differences between persons with MS due to gender, ethnicity, and age have been reported in several studies. Women and older persons with MS are more likely to be unemployed. ${ }^{34}$ They are also more likely to file an allegation of discrimination. ${ }^{35}$ By contrast, an Australian study found no differences in employment discrimination regarding gender or age. ${ }^{36}$ An American study showed that there are more similarities in employment discrimination than differences between women and men. ${ }^{37}$ Regarding ethnicity, previous studies were consistent with their results. Allegations of employment discrimination were more common among non-Caucasian persons with MS in the US. ${ }^{35}$ Several studies 
Table 2 Distribution of Charted Categories Among Included Articles with Examples of Key Results

\begin{tabular}{|l|l|}
\hline Charted category in Percent & Examples of Key Results \\
\hline Employment 39\% & $\begin{array}{l}\text { Discrimination due to being open about MS } \\
\text { Lack of accommodations at work } \\
\text { Environmental inaccessibility }\end{array}$ \\
\hline Social welfare and social services 18\% & $\begin{array}{l}\text { Economic hardship due to limited welfare benefits } \\
\text { Lack of financial support for accommodations at home } \\
\text { Insufficient help from social services }\end{array}$ \\
\hline Transportation 14\% & $\begin{array}{l}\text { Lack of accessible parking } \\
\text { Inaccessible public transportation } \\
\text { Inconvenient transport for disabled people }\end{array}$ \\
\hline Home/public place accessibility 12\% & $\begin{array}{l}\text { Lack of necessary accommodations at home } \\
\text { Inaccessible public spaces } \\
\text { Inaccessible public buildings }\end{array}$ \\
\hline Health services 10\% & $\begin{array}{l}\text { Facing negative attitudes } \\
\text { Inaccessible facilities } \\
\text { Cost of services }\end{array}$ \\
\hline Negative attitudes from others 7\% & $\begin{array}{l}\text { Misunderstandings about MS } \\
\text { Staring } \\
\text { Being questioned due to invisible symptoms of MS }\end{array}$ \\
\hline
\end{tabular}

showed that the employment rates were low for non-Caucasian Americans with MS. Hispanics, Afro-Americans, and Afro-American women with MS all had low levels of employment in the US. ${ }^{35,38,39}$ In a recent American study on work loss due to the Covid-19 pandemic, it was found that non-Caucasian persons with MS reported work loss to a higher extent than those identifying as white. ${ }^{33}$

Several studies showed that persons with MS fear they will not be employable or have been rejected, due to being open about their MS, eg. ${ }^{40-42}$ Disclosure of diagnosis was a difficult question for persons with MS because of fear of discrimination. ${ }^{43}$ In different studies, persons with MS who had disclosed their diagnosis reported more problems at work, eg. ${ }^{42,44,45}$ However, an Australian study found that persons with MS who had disclosed their diagnosis were more likely to stay employed than those who had not made a disclosure. ${ }^{36}$

A frequently reported problem for persons with MS was accommodations at the workplace due to environmental inaccessibility, eg. ${ }^{28,30,46}$ Several studies showed that obtaining the necessary accommodations at the workplace is not easy for persons with MS, eg. ${ }^{47-49}$ In American studies of allegations of workplace discrimination, a lack of accommodations was a common problem for persons with $\mathrm{MS} .{ }^{48,50} \mathrm{~A}$ lack of accommodations was a more frequent problem for persons with MS compared to persons with other diseases in a comparative study. ${ }^{50}$ Studies have reported that persons with MS avoid asking for accommodations to some extent because of a fear of discrimination, eg. ${ }^{41,44,49}$ An American study revealed that a large proportion of the accommodations used by persons with MS at work were not preceded by a formal request to the employer, meaning that the employer was not involved in arranging the accommodations. ${ }^{51}$ Due to the shifting character of the disease for persons with relapsing MS, for example, needs for accommodations were questioned. ${ }^{47}$ In a study consisting only of women with MS, the results showed that accommodations were more often arranged for those with some kind of specialized competence. ${ }^{52}$

Studies revealed various examples of employment discrimination by supervisors and colleagues. Persons with MS were questioned about their competence due to their disease. ${ }^{41,53}$ Examples of reported consequences include receiving unreasonable supervision ${ }^{54,55}$ or a downgrade in responsibilities at work. ${ }^{45,56,57}$ In other cases, persons with MS were assigned excessive responsibilities with the intention to make them leave work. ${ }^{45,58}$ Semi-voluntary transitions at work or from work were described in some studies. ${ }^{42,59}$ Negative attitudes from co-workers were described in several studies, such as being questioned due to the shifting character of the MS disease and experiencing social isolation at work, eg. ${ }^{41,60,61}$ 


\section{Social Welfare and Social Services}

In this section, articles focusing wholly or partially on social welfare and social services will be presented. In total, 26 articles were charted in this category. Articles were evenly distributed between Europe, North America, Asia, and Australia.

A lack of financial support from the welfare state was presented as a barrier in many studies. The economic hardship that persons with MS face is the most frequently presented barrier, meaning that, in many cases, persons with MS who cannot earn a living from employment and have to rely on the welfare state have poor economic conditions. This was evident in studies from various countries, eg. ${ }^{52,62-64} \mathrm{~A}$ lack of financial support with which to provide accommodations at home for persons with MS was evident in several studies, eg. ${ }^{65-67}$ Inadequate economic support for transportation and mobility aids was presented in several studies, eg. ${ }^{62,68,69}$ The financial limitations also affected persons with MS in relation to health care. Two studies from different contexts presented results concerning persons with MS and their health care. $^{70,71}$ Both the US and Malaysia have publicly funded health care to some extent, as well as an extensive private health care sector. According to these studies, persons with MS are a vulnerable group because private health insurance can often be a benefit for employed individuals. ${ }^{70,71}$ Due to insecurity regarding their right to health care, high levels of stress and worries, and postponed care-seeking were reported from the US. ${ }^{70}$ As disease-modifying therapies for MS are expensive, persons with MS were reported to be at risk of not getting adequate treatment due to deficient social welfare systems. ${ }^{70,71}$

Social services, a part of the social welfare system, were reported as a barrier in certain studies. Bureaucracy within the system and access to services are problems for persons with MS. ${ }^{64,68,72}$ Another problem reported in studies is that persons with MS are not being provided with information about available assistance and who is eligible. ${ }^{69,72}$ Further, one study showed that a barrier for persons with MS is a long waiting process to get the help needed and a lack of continuity in the help. ${ }^{72}$ Regarding assistance from social services, several studies presented this as a barrier to independent living, eg. ${ }^{67,73,74}$ Two Italian survey studies reported a lack of personal assistance. ${ }^{64,66}$ In a study from the UK, insufficient support restricted the choices persons with MS can make and their possibility to live an independent life. Restricted choices and control lead to persons with MS living in social isolation. ${ }^{75}$

\section{Transportation}

Twenty articles were charted as including transportation issues in relation to disability. These articles were derived from Europe, Asia, Australia, and North America. In almost all these articles, the foci were combined between transportation and other disability issues, as transportation was often one of the many barriers presented in the results. Transportation in general has been termed a barrier in many studies without defining which aspects constitute particular obstacles. $^{30,76,77}$

Accessible parking was a transportation-related problem described in several studies. The lack of accessible parking was a problem for persons with MS when they came into contact with health services, such as medical visits and physiotherapy, eg. ${ }^{78-80}$ The problem of a lack of accessible parking was also evident in studies that primarily highlighted the employment situation for persons with MS, eg. ${ }^{28,81,82}$

Two of the included studies specified that public transportation and mobility aids were barriers for persons with MS. ${ }^{69,83}$ A large American survey study presented several shortages in relation to public transportation. ${ }^{67}$ Public transportation was not available to many of Americans. In many cases where it was available, it did not meet the needs of persons with MS. Several barriers were noted: non-working elevators or escalators, a lack of ramps, fear of being caught in doors, and unreasonable terms for using transportation. The latter was exemplified by the requirement to make a reservation several days ahead of a planned trip. The time required for a trip was sometimes many hours, even though the errand might be a short doctor's appointment. ${ }^{67}$

\section{Home/Public Place Accessibility}

This section focuses on accessibility in the homes of persons with MS and in public places. It consists of seventeen articles, and countries from Europe, Asia, and North America are represented. 
In a large American survey, about $20 \%$ of persons with MS answered that their residential accessibility was limited. Respondents in this survey gave several examples of home areas with limited or no accessibility: bathroom, kitchen, entrance to home, and bedroom. The need for an elevator or a stairlift was also evident. ${ }^{84,85}$ Several of these barriers at home were present in a study from Jordan. ${ }^{73}$ According to the literature, accommodations at home are a problem for persons with MS who need them, eg. ${ }^{66-68}$

Inaccessible public spaces are frequently reported as a barrier for persons with MS, eg. ${ }^{66,86,87}$ Due to the various symptoms of MS, including bladder dysfunction, a lack of restrooms or inaccessible restrooms was a recurrent barrier, eg. ${ }^{73,88,89}$ According to the literature, public buildings that were unsuitable for persons with MS included restaurants, stores, malls, and cafés. Further, the design of streets, pavements, and parks was a barrier, eg. ${ }^{29,73,89}$ The environmental inaccessibility of public buildings and public places was reported to lead to social isolation ${ }^{75}$ and lower participation in society. ${ }^{86,87}$

\section{Health Services}

The category of health services includes both medical health care visits, such as doctor's and nurse's appointments, and rehabilitation or exercise services, including gyms and swimming facilities. Fifteen studies were charted in this category. Most of the studies were from the US, and the rest were conducted in the UK, Australia, and Canada.

Even though medical clinics exist to serve people with health problems and their various symptoms, there was evidence of inaccessible facilities. ${ }^{79,80,90}$ Obstacles that were mentioned in the literature related to entrances, doorways that were too narrow, curb cuts, a lack of ramps, restrooms, examination rooms, and medical equipment. ${ }^{79,90}$ Studies highlighted other forms of inaccessibility and dysfunctional care, including a lack of nearby care, ${ }^{79,91}$ and access to secondary health services, such as specialist care, neurology, physiotherapy, and rehabilitation. ${ }^{90,92}$ The cost of services and unreasonable paperwork were other barriers to access to health care. ${ }^{79,80,90}$

The cost of services was also a barrier, according to the studies concerning rehabilitation and exercise. ${ }^{93-95}$ Inaccessible facilities were presented as a barrier to rehabilitation activity and exercise in several studies, eg. ${ }^{78,96,97}$ A lack of support from physical activity personnel was another obstacle mentioned in several studies, eg. ${ }^{94,95,98}$ Negative attitudes from others in the context of exercise were a frequent barrier, according to the literature. This might take the form of disbelief of disease for persons with MS because they appear able-bodied, since they are able to exercise. ${ }^{96}$ Staring from others was a concrete form of negative attitudes ${ }^{78}$ that might be connected to embarrassment about one's appearance in the gym. ${ }^{93}$

\section{Negative Attitudes from Others}

Even though negative attitudes from others were presented in the previous sections, this section is about negative attitudes from others within society in general. Eleven articles were charted in this category. The most frequent national origin in this section was Iran $(n=4)$, and these Iranian articles constituted $80 \%$ of this scoping review's total Iranian studies.

In the Iranian context, studies reported what Dehghani, Khoramkish, and Shahsavari Isfahani ${ }^{63}$ refer to as culturalsocial wrong beliefs. Examples of cultural-social wrong beliefs were the misunderstanding that MS is a contagious disease, ${ }^{40,63}$ the person with MS being given overemphasized sympathy or pity, ${ }^{40,99}$ the belief that the person with MS will rapidly be forced to use a wheelchair and that the disease will soon lead to the death, ${ }^{29,40,63}$ and staring as a way of experiencing the negative attitudes of others. ${ }^{40,99}$ A general picture of negative attitudes against persons with MS and a lack of awareness about the disease were pointed out in the Iranian context. ${ }^{29,99}$ In a survey study, a large proportion answered that they prefer to hide their disease from others, that they feel discomfort in social situations because of their MS, that they have reduced social activity due to others' attitudes, and that they have lost friends due to their disease. ${ }^{99}$ A study from Jordan reported that persons with MS experienced the attitudes of their family and relatives as a barrier. ${ }^{73}$

Negative attitudes from others were not exclusive to the Iranian or Middle Eastern contexts. These attitudes were, among other barriers, what constituted restrictions in societal participation for persons with MS, eg. ${ }^{83,87,100}$ Because of the variety of symptoms of MS, some of them may be visible, while others may not be. Invisible symptoms were reported as leading to negative attitudes from others who questioned the person with MS and their abilities. ${ }^{61,88}$ Negative attitudes 
could also take the form of others telling the person with MS that they should be in some kind of medical care and not be with "normal" people. ${ }^{88}$ In a qualitative study, examples were given from women's lives where invisible symptoms created constant situations of negotiations. Appearing to be able-bodied, meaning free from impairment, made it hard for others to understand and believe someone who talks about their symptoms and the problems they create. Because of these invisible symptoms, persons with MS were questioned, and their abilities were taken for granted since they look "normal". ${ }^{1}$

\section{Discussion}

This scoping review is, to our knowledge, the first to focus on disability, according to the social model, for persons with MS. Using the social model of disability - a model of equal rights for people - is a novel design in a field that has traditionally been dominated by medical research. In addition to the medical perspective, the social model perspective allows conditions for persons with MS in society to be highlighted, in line with the Convention on the Rights of Persons with Disabilities and its Optional Protocol. ${ }^{1}$ A rising number of articles were included when comparing every five-year period from 2000-2004 to 2015-2019. However, it remains to be seen whether the tendency continues.

\section{Employment Discrimination}

Employment discrimination was the most common disability topic in the included articles. In an American study, the employment rates for persons with MS were lower than 40\%. In their concluding discussion, the authors pointed out a need for improved policies and services to help persons with MS enter, re-enter, or keep their employment. ${ }^{31}$ Another American study showed that the legal protection for employees with impairments in the US have been strengthened since the early 1990s, with the emphasis shifting from the individual to the disabling surroundings. ${ }^{35}$ However, the protection was still not sufficient. ${ }^{35,101}$ From the American studies, legal protection from employment discrimination was a recurrent subject that was discussed as affecting persons with MS. It was shown that the legal protection may vary between different states ${ }^{35}$ and it was argued that this protection was not adequate, ${ }^{31}$ as the results from many studies support.

An Australian study showed that persons with MS were less frequently employed than the general population, ${ }^{30}$ similar to what was reported from the US context. However, a more recently published study contradicted these results, showing that the employment gap had been reduced. ${ }^{32}$ A plausible explanation for the positive results from Australia is that the government offers financial assistance to employers that support their disabled employees with accommodations and other forms of support. ${ }^{32}$ As a result, the number of successful requests for accommodations was higher than the reported number from the US. However, the study ${ }^{32}$ also showed that persons with MS reported fear of discrimination and, as a consequence, never asked for accommodations, consistent with the findings of many other included studies, eg. ${ }^{41,44,49}$ A study comparing disability-related employment laws and policies in 193 countries showed that approximately half of the countries had deficient protection for disabled people. ${ }^{102}$ The US was taken as an example of where reasonable accommodations are mandated. Still, it was shown that under $30 \%$ of older persons with impairment received any accommodations from their employer. Heymann et al ${ }^{102}$ discussed that a cost-sharing system with state financial incentives may be a solution to improve conditions for disabled people, which is in line with what Van Dijk et al ${ }^{32}$ suggested as a significant reason for the positive Australian results. Future studies would benefit from having a comparative design to broaden the state of knowledge.

\section{Societal Deficiencies}

Studies also offered evidence of several additional disabling barriers related to society, for example, limited financial support for daily living, ${ }^{64}$ inaccessible public buildings, ${ }^{73}$ and dysfunctional transportation. ${ }^{67}$ Many similar barriers were identified for persons with MS regardless of national context, although there were some variations between countries. In studies from the US and Malaysia, it was found that access to health care is often an employment benefit, ${ }^{70,71}$ meaning that one must be employed to have access to adequate health care. As discussed above, persons with MS face several barriers in relation to employment. The Malaysian case also showed that employment was not a guarantee for getting 
adequate health care. ${ }^{71}$ Such health care systems put persons with MS in a particularly vulnerable situation, as previous research has shown that they are employed to a lesser extent.

Studies focusing on social welfare and social services, transportation, and accessibility of homes and public places discussed their results with different foci. Some authors addressed their results in terms of societal deficiencies on a macro level. The Malaysian results were discussed as gaps in the structural protection for persons with MS, which made it possible for an employer to stop paying for an employee's health care. ${ }^{71}$ In the US, the health insurance system was addressed as inadequate for a considerable proportion of employed persons with $\mathrm{MS},{ }^{70}$ and the social security benefits were also pointed out as being deficient. ${ }^{67}$ In Italy, the well-established differences in the accessibility of social services and health services depending on geographical location were highlighted. ${ }^{64}$ National differences in rights for persons with MS in relation to employment were emphasized in a study that compared conditions in Austria and Switzerland. ${ }^{87}$

It is evident that disabling barriers may vary depending on the national context. However, it was found that most of the represented studies were conducted in nations regularly classified as liberal welfare states, involving low influence from the state and a more limited public social protection system than, for example, the Nordic countries. ${ }^{103}$ Whether this is an explanation - at least in part - is not revealed in the included studies. This is an area where more comparative research would improve the state of knowledge.

\section{Negative Attitudes in Society: Cultural Context}

A striking finding was that among the articles in the category of negative attitudes from others, a substantial number of them were from Iran. Similar negative attitudes were reported from Jordan, another Middle Eastern country. Negative attitudes from others were reported in studies from other contexts, but specifically in relation to employment or health services. What differs was that the Iranian and Jordanian studies addressed negative attitudes towards persons with MS from family members, acquaintances, and people within society in general. This was referred to as cultural-social wrong beliefs. ${ }^{63}$ From a micro-level perspective, the included studies gave evidence that persons with MS in Iran and Jordan might live a very limited social life. Even though negative attitudes exist in other national contexts, it is worth noting the differences as the negative attitudes reported from Iran and Jordan were especially from relatives, acquaintances, and others within society. On a macro level, this might be the result of a general lack of knowledge about MS in society, which is expressed through incorrect beliefs about the disease. Another Iranian study on attitudes against disabled people concluded that Iran had a patriarchal characteristic which excludes disabled people and disabled women in particular. ${ }^{104}$ The findings are based on few studies, and more research is needed to increase knowledge about the relationship between negative attitudes in society and cultural context.

\section{Gender, Age, and Ethnicity}

The vast majority of the included studies had both female and male persons with MS in their samples. As expected, the samples were often dominated by females, which is in line with the higher prevalence of MS among women. ${ }^{5,6}$ It was found that few articles involved studying gender differences, and those that involved comparisons were mostly concentrated on employment discrimination. Even fewer studies using age as a variable affecting persons with MS were found. Those that involved age were almost all studies that also examined employment discrimination. Both female gender and higher age were negatively associated with employment. ${ }^{34}$ Women and older persons with MS were also more likely to experience discrimination. ${ }^{35}$ The results were in line with research on age-related employment discrimination among the general population, where older persons and especially older women received fewer callbacks from employers with vacancies in various occupations. ${ }^{105}$

The pattern of ethnicity was the same as for gender and age, and only a few American employment-focused studies took this perspective. From these studies, it is known that the employment rates for non-Caucasian Americans with MS are low, eg. ${ }^{38}$ An American survey study on employment states that African American women with MS are a group that has been given very little attention. ${ }^{39}$ Ethnic discrimination in the labor market has been documented among the general population as well. ${ }^{106}$ Rumrill et al ${ }^{39}$ point out that African American women may be exposed to a triple disadvantage, considering gender, ethnicity, and their impairment. It is concluded that further research is needed. ${ }^{39}$ An interactive effect 
of different variables - eg gender, age, ethnicity, and impairment - has been shown to be significant, with a higher risk of experiencing discrimination in relation to employment ${ }^{107}$ and a greater risk of living in poverty ${ }^{108}$ in studies including persons with different impairments.

The American dominance in studies including gender, age, and ethnicity shows a research gap where more knowledge is needed from other national contexts. These variables are largely missing in studies from European countries with substantial minority populations. In line with what Rumrill et $\mathrm{al}^{39}$ point out, people with MS from minority groups might be exposed to greater risks of discrimination and barriers.

\section{Invisible Symptoms of MS}

MS can involve having one or more invisible symptoms, for example, impaired vision and fatigue, ${ }^{5}$ meaning that other people cannot see the person's impairment. These invisible symptoms have been shown to be common among persons with MS, even when they are clinically classified as not being particularly affected by their disease. ${ }^{109}$ This is not unique to MS, as other diseases can also have symptoms that are not visible, eg. ${ }^{110}$ However, the literature provided examples of how MS symptoms were related to societal barriers. American studies that compared persons with MS to a group including persons with other diseases or impairments showed that persons with MS more often experienced problems getting the accommodations they needed at work. ${ }^{50,101}$ Two studies described the shifting character of the disease as a factor that resulted in the needs of persons with MS being questioned in the employment context. ${ }^{47,51}$ The progressive character of two common invisible symptoms - fatigue and cognitive impairment - was discussed as being problematic in terms of getting reasonable accommodations. ${ }^{101}$ The questioning of capacities was highlighted in studies focusing on attitudes from others within society, ${ }^{61,88}$ and from the exercise context. ${ }^{96}$ What was more rarely discussed in studies was the significance of invisible symptoms, meaning that people with impairments that are not visible may face the same disabling barriers as persons with visible impairments, but that there are also additional barriers, such as being questioned by others. One difference when comparing visible and invisible impairments might be that the former is less likely to result in people being questioned about the "authenticity" of their symptoms. A study that included persons with acquired brain injury, and thus experiencing invisible symptoms, showed that these persons faced similar barriers to persons with MS in relation to other persons, in their employment situation, in their contact with social services, and in their contact with health services. ${ }^{110}$ Invisible symptoms in relation to disability for persons with MS were found to be an area where more research is needed. A specific area for future studies might be invisible symptoms in relation to access to social services and daily help, as no research was found on this subject.

\section{Implications for Future Research}

Studies conducted by scholars from several fields were included in this scoping review, for example, social work, ${ }^{61}$ nursing, ${ }^{111}$ medicine, ${ }^{112}$ rehabilitation, ${ }^{113}$ and psychology. ${ }^{60}$ The interdisciplinary research teams mostly consisted of scholars from medicine and health sciences. A substantial majority of the authors of the included articles were from fields related to medicine and health. On one hand, this showed that the social perspective was taken by researchers interested in social rights for persons with MS, regardless of their scientific domicile. On the other hand, it became evident that social science research on persons with MS and disability is scarce.

A recurrent observation, both in reading studies about MS as a disease ${ }^{5,8,9}$ and among the selected studies for this review, ${ }^{30,114,115}$ is the conceptual confusion that might strike a reader. It is problematic that the concept of disability is used in different ways and can signify both individual deficits and societal barriers. Even though it is often recognized that people can be disabled by both their bodies and society, ${ }^{116}$ a unified use of the concepts of impairment and disability would remove some conceptual confusion.

Methodologically, the included studies were mostly quantitative, but qualitative studies also constituted a considerable proportion. There were few mixed methods studies and longitudinal studies. Longitudinal studies provide evidence of potential changes over time and are therefore an important contributor to the state of knowledge. An Australian longitudinal study ${ }^{32}$ contradicted other discouraging results on persons with MS and employment, and was therefore an important contributor to the overall knowledge. There were also few studies that took a collaborative approach, involving persons with MS in some way other than as the studied population. ${ }^{117}$ This is an area where more 
research may be conducted and where future knowledge production can be based on what persons with MS consider important.

Several research gaps have been addressed in this scoping review. The most obvious implication for future research is the need for more knowledge on disability for persons with MS from various contexts, as previous research has been dominated by studies conducted in the US. The articles from European countries accounted for a rather small share of the total sample $(\mathrm{n}=24)$, and only one Nordic study was included. No articles from countries in South America or Africa were included.

Employment discrimination was the dominant area of research. This is an important area of life where research from other contexts may add to the state of knowledge. It is, however, suggested that more research should be conducted on the societal areas that have been discussed in this scoping review: social welfare, social services, access to health services, accessibility at public places, and equal opportunities to use transportation. Some areas that were not specifically addressed in the included research but are included in the Convention on the Rights of Persons with Disabilities and Optional Protocol ${ }^{1}$ are family life, leisure time, and education. The latter constitutes a clear research gap, considering that many persons with MS are diagnosed at an age where they may invest in education.

\section{Implications for Clinical Practice}

This scoping review presents several areas where persons with MS are disabled in society, for example, in work-life, in daily life, and not at least in relation to health services. Such knowledge is important for clinical practitioners within all professions in healthcare when taking care of persons with MS. Healthcare professionals need to utilize a holistic perspective, seeing beyond the medical aspects of the disease. As has been shown, persons with MS are not only affected by their symptoms and impairment but to a considerable extent by societal barriers and discrimination. To ensure that clinical healthcare practice offers an adequate support and work to eliminate disabling barriers and discrimination, these aspects of persons with MS's lives need to be observed and expressed. Thus, involved professionals need to ask about and assess the person in relation to their social environment. A central part of a more adequate care of persons with MS is a multidisciplinary healthcare team, where professionals with various disciplinary backgrounds can identify resources as well as barriers in a person's situation and arrange adequate support where needed.

\section{Limitations and Strengths}

A limitation of this scoping review is the English language only criterion. This inclusion criteria may have implied that relevant studies were overlooked. The included studies were dominated by articles from nations where English is the primary language and the language criterion may, at least in part, be an explanation for this. Another limitation might have been the use of social model of disability-specific search terms. However, many studies were found that did not take the social model of disability perspective but still focused on disabling societal aspects of living for persons with MS, which strengthens the chosen methodological approach. When carrying out the citation search and the reference list search, it was noted that several of the initially included articles were frequently seen in both reference lists and citations, which indicates that relevant articles were found. By using the team approach when reviewing the articles, the risk of individual bias was reduced.

\section{Conclusions}

This scoping review contributes by synthesizing existing knowledge on persons with MS and disability. In the review, it was found that research on persons with MS and disability has mainly been conducted in the US and is focused on employment discrimination. Existing research shows that persons with MS face disabling barriers and discrimination in relation to employment, social welfare and social services, transportation, homes and public places, health services, and in relation to others within society. Several research gaps were found in areas where research was non-existent or limited. To better understand MS and disability, there is a need for studies from various national contexts and welfare systems, including research on employment discrimination and work-related rights, the importance of cultural context, the impact of gender, age, and ethnicity, and the invisible symptoms of MS. Such research is needed to inform necessary policy changes to include persons with MS in society in line with the Convention on the Rights of Persons with Disabilities and its Optional Protocol. Implications for clinical healthcare were suggested based on the findings. 


\section{Acknowledgments}

Many thanks to David Kjellin, librarian at the University of Gothenburg library, for excellent help and guidance in the initial phase of the study.

\section{Disclosure}

The authors have no conflicts of interest in this work to declare.

\section{References}

1. United Nations. Convention on the Rights of Persons with Disabilities (CRPD); 2021. Available from: https://www.un.org/development/desa/ disabilities/convention-on-the-rights-of-persons-with-disabilities.html. Accessed May 2, 2021.

2. The Multiple Sclerosis International Federation. Atlas of MS. 3rd ed. The Multiple Sclerosis International Federation; 2020.

3. The Multiple Sclerosis International Federation. Atlas of MS: Mapping Multiple Sclerosis Around the World. The Multiple Sclerosis International Federation; 2013.

4. Wallin MT, Culpepper WJ, Campbell JD, et al. The prevalence of MS in the United States: a population-based estimate using health claims data. Neurology. 2019;92(10):e1029-e1040. doi:10.1212/WNL.0000000000007035

5. Filippi M, Bar-Or A, Piehl Fet al. Multiple sclerosis. Nat Rev Dis Primers. 2018;4(1):43. doi:10.1038/s41572-018-0041-4

6. Bowen J, Mehta R, Pelletier C, et al. Treatment patterns among patients with multiple sclerosis initiating second-line disease-modifying therapy. Adv Ther. 2020;37(7):3163-3177. doi:10.1007/s12325-020-01367-1

7. Oliver M. Understanding Disability: From Theory to Practice. New ed. London: Macmillan; 1996.

8. Batcheller L, Baker D. Cost of disease modifying therapies for multiple sclerosis: is front-loading the answer? J Neurol Sci. 2019;404:19-28. doi:10.1016/j.jns.2019.07.009

9. Thompson AJ, Banwell BL, Barkhof F, et al. Diagnosis of multiple sclerosis: 2017 revisions of the McDonald criteria. Lancet Neurol. $2018 ; 17$ (2):162-173. doi:10.1016/S1474-4422(17)30470-2

10. Morris J. Impairment and disability: constructing an ethics of care that promotes human rights. Hypatia. 2001;16(4):1-16. doi:10.1111/j.15272001.2001.tb00750.x

11. Shakespeare T, Watson N. The social model of disability: an outdated ideology? In: Barnartt SN, Altman BM, editors. Exploring Theories and Expanding Methodologies: Where We are and Where We Need to Go. Vol. 2. Emerald Group Publishing Limited; 2001:9-28.

12. Gil-González I, Martín-Rodríguez A, Conrad R, Pérez-San-Gregorio MÁ. Quality of life in adults with multiple sclerosis: a systematic review. BMJ Open. 2020;10(11):e041249. doi:10.1136/bmjopen-2020-041249

13. Koutsogeorgou E, Chiesi AM, Leonardi M. Social capital components and social support of persons with multiple sclerosis: a systematic review of the literature from 2000 to 2018. Disabil Rehabil. 2020;42(24):3437-3449. doi:10.1080/09638288.2019.1597182

14. Pashazadeh Kan F, Hoseinipalangi Z, Ahmadi N, et al. Global, regional and national quality of life in patients with multiple sclerosis: a global systematic review and meta-analysis. BMJ Support Palliat Care. 2020;bmjspcare-2020-002604. doi:10.1136/bmjspcare-2020-002604

15. Fisher PL, Salmon P, Heffer-Rahn P, Huntley C, Reilly J, Cherry MG. Predictors of emotional distress in people with multiple sclerosis: a systematic review of prospective studies. J Affect Disord. 2020;276:752-764. doi:10.1016/j.jad.2020.07.073

16. Topcu G, Griffiths H, Bale C, et al. Psychosocial adjustment to multiple sclerosis diagnosis: a meta-review of systematic reviews. Clin Psychol Rev. 2020;82:101923. doi:10.1016/j.cpr.2020.101923

17. Paz-Zulueta M, Parás-Bravo P, Cantarero-Prieto D, Blázquez-Fernández C, Oterino-Durán A. A literature review of cost-of-illness studies on the economic burden of multiple sclerosis. Mult Scler Relat Disord. 2020;43:102162. doi:10.1016/j.msard.2020.102162

18. van Der Feen FE, de Haan GA, van Der Lijn I, Heersema DJ, Meilof JF, Heutink J. Independent outdoor mobility of persons with multiple sclerosis - a systematic review. Mult Scler Relat Disord. 2020;37:101463. doi:10.1016/j.msard.2019.101463

19. Conradsson D, Ytterberg C, Engelkes C, Johansson S, Gottberg K. Activity limitations and participation restrictions in people with multiple sclerosis: a detailed 10-year perspective. Disabil Rehabil. 2021;43(3):406-413. doi:10.1080/09638288.2019.1626919

20. Kesselring J, Beer S. Symptomatic therapy and neurorehabilitation in multiple sclerosis. Lancet Neurol. 2005;4(10):643-652. doi:10.1016/ S1474-4422(05)70193-9

21. Khan F, Turner-Stokes L, Ng L, Kilpatrick T, Amatya B, Khan F. Multidisciplinary rehabilitation for adults with multiple sclerosis. Cochrane Library. 2007;2011(12):CD006036.

22. Arksey H, O’Malley L. Scoping studies: towards a methodological framework. Int J Soc Res Methodol. 2005;8(1):19-32. doi:10.1080/ 1364557032000119616

23. Levac D, Colquhoun H, O’Brien KK. Scoping studies: advancing the methodology. Implement Sci. 2010;5(1):69. doi:10.1186/1748-5908-5-69

24. Tricco AC, Lillie E, Zarin W, et al. PRISMA extension for scoping reviews (PRISMA-ScR): checklist and explanation. Ann Intern Med. 2018;169(7):467. doi:10.7326/M18-0850

25. Sucharew H, Macaluso M. Progress notes: methods for research evidence synthesis: the scoping review approach. J Hosp Med. 2019;14 (7):416-418. doi: $10.12788 / \mathrm{jhm} .3248$

26. Khan F, Amatya B, Ng L. Use of the international classification of functioning, disability and health to describe patient-reported disability: a comparison of Guillain Barré syndrome with multiple sclerosis in a community cohort. $J$ Rehabil Med. 2010;42(8):708. doi:10.2340/ 16501977-0592

27. Broersma F, Oeseburg B, Dijkstra J, Wynia K. The impact of self-perceived limitations, stigma and sense of coherence on quality of life in multiple sclerosis patients: results of a cross-sectional study. Clin Rehabil. 2018;32(4):536-545. doi:10.1177/0269215517730670

28. Carrieri L, Sgaramella TM, Bortolon F, et al. Determinants of on-the-job-barriers in employed persons with multiple sclerosis: the role of disability severity and cognitive indices. Work. 2014;47(4):509-520. doi:10.3233/WOR-131623

29. Farmani O, Taher M, Maarefvand M, et al. Rehabilitation services difficulties perceived by multiple sclerosis patients, their families and professionals in Iran: a qualitative study. Middle East J Fam Med. 2018;7(10):53-59. 
30. Simmons RD, Tribe KL, McDonald EA. Living with multiple sclerosis: longitudinal changes in employment and the importance of symptom management. J Neurol. 2010;257(6):926-936. doi:10.1007/s00415-009-5441-7

31. Rumrill PD, Roessler R, Li J, Daly K, Leslie M. The employment concerns of Americans with multiple sclerosis: perspectives from a national sample. Work (Reading, Mass). 2015;52(4):735-748. doi:10.3233/WOR-152201

32. Van Dijk PA, Kirk-Brown AK, Taylor B, van der Mei I. Closing the gap: longitudinal changes in employment for Australians with multiple sclerosis. Multiple Sclerosis. 2017;23(10):1415-1423. doi:10.1177/1352458516678934

33. Bishop M, Rumrill SP. The employment impact of the COVID-19 pandemic on Americans with MS: preliminary analysis. $J$ Vocat Rehabil. 2021;54(1):81-87. doi:10.3233/JVR-201120

34. Lehmann AI, Rodgers S, Kamm CP, et al. Factors associated with employment and expected work retention among persons with multiple sclerosis: findings of a cross-sectional citizen science study. J Neurol. 2020;267(10):3069-3082. doi:10.1007/s00415-020-09973-3

35. Roessler RT, Rumrill PD, Li J, McMahon BT. The workplace discrimination experiences of people with multiple sclerosis across three phases of Americans with disabilities act implementation. J Vocat Rehabil. 2016;45(1):27-41. doi:10.3233/JVR-160808

36. Kirk-Brown AK, Van Dijk PA, Simmons RD, Bourne MP, Cooper BK. Disclosure of diagnosis of multiple sclerosis in the workplace positively affects employment status and job tenure. Multiple Sclerosis J. 2014;20(7):871-876. doi:10.1177/1352458513513967

37. Rumrill PD, Roessler RT, McMahon BT, Hennessey ML, Neath J. Gender as a differential indicator of the employment discrimination experiences of Americans with multiple sclerosis. Work. 2007;29(4):303-311.

38. Roessler RT, Rumrill PD, Li J, Daly K, Anhalt K. High-priority employment concerns of Hispanics/Latinos with multiple sclerosis in the United States. J Vocat Rehabil. 2016;45(2):121-131. doi:10.3233/JVR-160817

39. Rumrill PD, Wu R, Goldstein P, et al. Importance and satisfaction ratings on 38 key employment concerns among African American women with multiple sclerosis. J Vocat Rehabil. 2020;52(2):173-183. doi:10.3233/JVR-191068

40. Abolhassani S, Yazdannik A, Taleghani F, Zamani A. Social aspects of multiple sclerosis for Iranian individuals. Disabil Rehabil. 2015;37 (4):319-326. doi:10.3109/09638288.2014.918192

41. Bogenschutz M, Inge KJ, Rumrill PD, Hinterlong PC, Seward HE. Barriers to and facilitators of employment among Americans with multiple sclerosis: results of a qualitative focus group study. J Rehabil. 2016;82(2):59-69.

42. Vijayasingham L, Jogulu U, Allotey P. Chronic illness and sustainable careers: how individuals with multiple sclerosis negotiate work transitions in a middle-income country. Soc Sci Med. 2020;245:112699. doi:10.1016/j.socscimed.2019.112699

43. Cook JE, Salter A, Stadler G. Identity concealment and chronic illness: a strategic choice. J Soc Issues. 2017;73(2):359-378. doi:10.1111/ josi.12221

44. Frndak SE, Kordovski VM, Cookfair D, Rodgers JD, Weinstock-Guttman B, Benedict RHB. Disclosure of disease status among employed multiple sclerosis patients: association with negative work events and accommodations. Multiple Sclerosis J. 2015;21(2):225-234. doi:10.1177/ 1352458514540971

45. Vickers MH. Why people with MS are really leaving work: from a Clayton's choice to an ugly passage - a phenomenological study. Rev Disabil Stud. 2014;4(4).

46. O’Connor RJ, Cano SJ, Ramió I, Torrentà L, Thompson AJ, Playford ED. Factors influencing work retention for people with multiple sclerosis: cross-sectional studies using qualitative and quantitative methods. $J$ Neurol. 2005;252(8):892-896. doi:10.1007/s00415-005-0765-4

47. Brown P, Johnson K. Aging with a disability and state vocational rehabilitation services. Work. 2014;48(3):441-451. doi:10.3233/WOR-131781

48. Neath J, Roessler RT, McMahon BT, Rumrill PD. Patterns in perceived employment discrimination for adults with multiple sclerosis. Work. 2007;29(3):255-274.

49. Stone SD, Crooks VA, Owen M. Going through the back door: chronically ill academics' experiences as 'unexpected workers'. Soc Theory Health. 2013;11(2):151-174. doi:10.1057/sth.2013.1

50. Rumrill PD, Roessler RT, McMahon BT, Fitzgerald SM. Multiple sclerosis and workplace discrimination: the national EEOC ADA research project. J Vocat Rehabil. 2005;23(3):179-187.

51. Leslie M, Kinyanjui B, Bishop M, Rumrill PD, Roessler RT. Patterns in workplace accommodations for people with multiple sclerosis to overcome cognitive and other disease-related limitations. NeuroRehabilitation. 2015;37(3):425-436. doi:10.3233/NRE-151271

52. Dyck I, Jongbloed L. Women with multiple sclerosis and employment issues: a focus on social and institutional environments. Can J Occup Ther. 2000;67(5):337-346. doi:10.1177/000841740006700506

53. Johnson KL, Yorkston KM, Klasner ER, Kuehn CM, Johnson E, Amtmann D. The cost and benefits of employment: a qualitative study of experiences of persons with multiple sclerosis. Arch Phys Med Rehabil. 2004;85(2):201-209. doi:10.1016/S0003-9993(03)00614-2

54. Roessler RT, Rumrill P, Hennessey M, Nissen S, Neath J. The employment discrimination experiences of adults with multiple sclerosis. J Rehabil. 2011;77(1):20-30.

55. Vickers MH. Telling tales to share multiple truths: disability and workplace bullying - A semi-fiction case study. Employee Responsibil Nights J. 2015;27(1):27-45. doi:10.1007/s10672-014-9246-1

56. Kirk-Brown AK, Van Dijk PA. An empowerment model of workplace support following disclosure, for people with MS. Multiple Sclerosis J. 2014;20(12):1624-1632. doi:10.1177/1352458514525869

57. Vickers MH. "For the crime of being different ... ": multiple sclerosis, teams, and stigmatisation at work-lessons from a case study. Employee Responsibil Rights J. 2012;24(3):177-195. doi:10.1007/s10672-011-9186-y

58. Vickers MH. Bullying, disability and work: a case study of workplace bullying. Qual Res Organ Manage. 2009;4(3):255-272. doi:10.1108/ 17465640911002536

59. Vickers MH. Financial turning points and transitions for people with multiple sclerosis: towards sustainable employment outcomes. $J$ Manag Organ. 2012;18(3):346-362. doi:10.5172/jmo.2012.18.3.346

60. Lee EJ, Ditchman N, Thomas J, Tsen J. Microaggressions experienced by people with multiple sclerosis in the workplace: an exploratory study using Sue's taxonomy. Rehabil Psychol. 2019;64(2):179-193. doi:10.1037/rep0000269

61. Vick A. The embodied experience of episodic disability among women with multiple sclerosis. Disabil Soc. 2013;28(2):176-189. doi:10.1080/ 09687599.2012.699279

62. De Judicibus MA, McCabe MP. Economic deprivation and its effects on subjective wellbeing in families of people with multiple sclerosis. $J$ Ment Health. 2005;14(1):49-59. doi:10.1080/09638230500047828 
63. Dehghani A, Khoramkish M, Shahsavari Isfahani S. Challenges in the daily living activities of patients with multiple sclerosis: a qualitative content analysis. Int J Commun Based Nurs Midwifery. 2019;7(3):201-210. doi:10.30476/IJCBNM.2019.44995

64. Ponzio M, Tacchino A, Vaccaro C, Brichetto G, Battaglia MA, Messmer Uccelli M. Disparity between perceived needs and service provision: a cross-sectional study of Italians with multiple sclerosis. Neurol Sci. 2019;40(6):1137-1144. doi:10.1007/s10072-019-03780-z

65. Bishop M, Dennis KL, Bishop LA, Sheppard-Jones K, Bishop F, Frain M. The prevalence and nature of modified housing and assistive devices use among Americans with multiple sclerosis. $J$ Vocat Rehabil. 2015;42(2):153-165. doi:10.3233/JVR-150732

66. Ponzio M, Tacchino A, Zaratin P, Vaccaro C, Battaglia MA. Unmet care needs of people with a neurological chronic disease: a cross-sectional study in Italy on multiple sclerosis. Eur J Public Health. 2015;25(5):775-780. doi:10.1093/eurpub/ckv065

67. Roessler RT, Bishop M, Rumrill PD, et al. Specialized housing and transportation needs of adults with multiple sclerosis. Work. 2013;45 (2):223-235. doi:10.3233/WOR-2012-1455

68. Borreani C, Bianchi E, Pietrolongo E, et al. Unmet needs of people with severe multiple sclerosis and their carers: qualitative findings for a home-based intervention. PLoS One. 2014;9(10):e109679. doi:10.1371/journal.pone.0109679

69. McCabe M, Ebacioni KJ, Simmons R, McDonald E, Melton L. Satisfaction with service needs among people living with multiple sclerosis NeuroRehabilitation. 2015;36(2):167-173. doi:10.3233/NRE-151204

70. Iezzoni LI, Ngo L. Health, disability, and life insurance experiences of working-age persons with multiple sclerosis. Multiple Sclerosis. 2007;13 (4):534-546. doi:10.1177/1352458506071356

71. Vijayasingham L, Jogulu U, Allotey P. Challenges for accessing and financing high-cost medicines in multipayer systems: case studies of multiple sclerosis in Malaysia. Crit Public Health. 2019;29(1):74-83. doi:10.1080/09581596.2017.1403011

72. Edmonds P, Vivat B, Burman R, Silber E, Higginson IJ. 'Fighting for everything': service experience of people severely affected by multiple sclerosis. Multiple Sclerosis. 2007;13(5):660-667. doi:10.1177/1352458506071789

73. Hamed R. Environmental factors affecting the daily functioning of Jordanian individuals with multiple sclerosis. Int J MS Care. 2012;14 (4):169-178. doi:10.7224/1537-2073-14.4.169

74. Jalili N, Poursafa A, Khazaali K, et al. Investigating environmental barriers affecting participation in patient with multiple sclerosis. $J$ Rehabil. 2020;2-21. doi:10.32598/RJ.21.1.1627.2

75. Freeman J, Gorst T, Gunn H, Robens S. "A non-person to the rest of the world": experiences of social isolation amongst severely impaired people with multiple sclerosis. Disabil Rehabil. 2020;42(16):2295-2303. doi:10.1080/09638288.2018.1557267

76. Campbell E, Coulter E, Mattison P, McFadyen A, Miller L, Paul L. Access, delivery and perceived efficacy of physiotherapy and use of complementary and alternative therapies by people with progressive multiple sclerosis in the United Kingdom: an online survey. Mult Scler Relat Disord. 2017;12:64-69. doi:10.1016/j.msard.2017.01.002

77. Graham CW, Inge KJ, Wehman P, Seward HE, Bogenschutz MD. Barriers and facilitators to employment as reported by people with physical disabilities: an across disability type analysis. $J$ Vocat Rehabil. 2018;48(2):207-218. doi:10.3233/JVR-180929

78. Borkoles E, Nicholls AR, Bell K, Butterly R, Polman RCJ. The lived experiences of people diagnosed with multiple sclerosis in relation to exercise. Psychol Health. 2008;23(4):427-441. doi:10.1080/14768320701205309

79. Buchanan RJ, Stuifbergen A, Chakravorty BJ, Wang S, Zhu L, Kim M. Urban/rural differences in access and barriers to health care for people with multiple sclerosis. J Health Hum Serv Adm. 2006;29(3):360-375.

80. Finlayson M, Van Denend T, Shevil E. Multiple perspectives on the health service need, use, and variability among older adults with multiple sclerosis. Occup Ther Health Care. 2004;172004:5-25.

81. Ponzio M, Brichetto G, Zaratin P, Battaglia MA. Workers with disability: the case of multiple sclerosis. Neurol Sci. 2015;36(10):1835-1841 doi:10.1007/s10072-015-2265-3

82. Rumrill PD, Roessler R, Vierstra C, Hennessey M, Staples L. Workplace barriers and job satisfaction among employed people with multiple sclerosis: an empirical rationale for early intervention. $J$ Vocat Rehabil. 2004;20(3):177-183.

83. Khan F, Pallant JF. Use of international classification of functioning, disability and health (ICF) to describe patient-reported disability in multiple sclerosis and identification of relevant environmental factors. $J$ Rehabil Med. 2007;39(1):63-70. doi:10.2340/16501977-0002

84. Bishop M, Roessler RT, Rumrill PD, et al. The relationship between housing accessibility variables and employment status among adults with multiple sclerosis. J Rehabil. 2013;79(4):4-14.

85. Bishop M, Sheppard-Jones K, Roessler RT, Rumrill PD, Waletich B, Umeasiegbu V. Specialized housing needs of Americans with multiple sclerosis: descriptive results of a national analysis. $J$ Vocat Rehabil. 2013;39(2):111-125. doi:10.3233/JVR-130649

86. Plow MA, Finlayson M, Gunzler D, Heinemann AW. Correlates of participation in meaningful activities among people with multiple sclerosis J Rehabil Med. 2015;47(6):538-545. doi:10.2340/16501977-1948

87. Prodinger B, Weise AP, Shaw L, Stamm TA. A Delphi study on environmental factors that impact work and social life participation of individuals with multiple sclerosis in Austria and Switzerland. Disabil Rehabil. 2010;32(3):183-195. doi:10.3109/09638280903071883

88. Green G, Todd J. 'Restricting choices and limiting Independence': social and economic impact of multiple sclerosis upon households by level of disability. Chronic Illn. 2008;4(3):160-172. doi:10.1177/1742395307087457

89. Finlayson M, Van Denend T, Hudson E. Aging with multiple sclerosis. J Neurosci Nurs. 2004;36(5):245-251, 259. doi:10.1097/01376517200410000-00003

90. O’Day B, Dautel P, Scheer J. Barriers to healthcare for people with mobility impairments. Manag Care Q. 2002;10(3):41-51.

91. Turner A, Chapko M, Yanez D, et al. Access to multiple sclerosis specialty care. $P M$ \& R. 2013;5(12):1044-1050. doi:10.1016/j. pmrj.2013.07.009

92. Methley AM, Chew-Graham CA, Cheraghi-Sohi S, Campbell SM. A qualitative study of patient and professional perspectives of healthcare services for multiple sclerosis: implications for service development and policy. Health Soc Care Community. 2017;25(3):848-857. doi:10.1111/ hsc. 12369

93. Fakolade A, Latimer-Cheung A, Parsons T, Finlayson M. A concerns report survey of physical activity support needs of people with moderate-to-severe MS disability and family caregivers. Disabil Rehabil. 2019;41(24):2888-2899. doi:10.1080/09638288.2018.1479781

94. Moffat F, Paul L. Barriers and solutions to participation in exercise for moderately disabled people with multiple sclerosis not currently exercising: a consensus development study using nominal group technique. Disabil Rehabil. 2019;41(23):2775-2783. doi:10.1080/ 09638288.2018 .1479456 
95. Vanner E, Block P, Christodoulou CC, Horowitz BP, Krupp LB. Pilot study exploring quality of life and barriers to leisure-time physical activity in persons with moderate to severe multiple sclerosis. Disabil Health J. 2008;1(1):58-65. doi:10.1016/j.dhjo.2007.11.001

96. Adamson B, Kinnett-Hopkins D, Athari Anaraki N, Sebastião E. The experiences of inaccessibility and ableism related to physical activity: a photo elicitation study among individuals with multiple sclerosis. Disabil Rehabil. 2020;1-12. doi:10.1080/09638288.2020.1844315

97. Brown C, Kitchen K, Nicoll K. Barriers and facilitators related to participation in aquafitness programs for people with multiple sclerosis. Int J MS Care. 2012;14(3):132-141. doi:10.7224/1537-2073-14.3.132

98. Becker H, Stuifbergen A. What makes it so hard? Barriers to health promotion experienced by people with multiple sclerosis and polio. Fam Community Health. 2004;27(1):75-85. doi:10.1097/00003727-200401000-00008

99. Kalantari S, Karbakhsh M, Kamiab Z, Kalantari Z, Sahraian MA. Perceived social stigma in patients with multiple sclerosis: a study from Iran. Acta Neurologica Taiwanica. 2018;27(1):1-8.

100. Coenen M, Basedow-Rajwich B, König N, Kesselring J, Cieza A. Functioning and disability in multiple sclerosis from the patient perspective. Chronic Illn. 2011;7(4):291-310. doi:10.1177/1742395311410613

101. Rumrill PD, Roessler RT, McMahon BT, Leslie M, Strauser DR. Workplace discrimination allegations and outcomes involving charging parties with multiple sclerosis and other disabilities under Title I of the Americans with disabilities act amendments act: a causal comparative analysis. $J$ Vocat Rehabil. 2019;51(1):41-53. doi:10.3233/JVR-191024

102. Heymann J, Wong E, Waisath W. A comparative overview of disability-related employment laws and policies in 193 countries. J Disabil Policy Stud. 2021;104420732110063. doi:10.1177/10442073211006396

103. Arts WA, Gelissen J. Models of the welfare state. In: Castles FG, Leibfried S, Lewis J, Obinger H, Pierson C, editors. The Oxford Handbook of the Welfare State. Oxford: Oxford University Press; 2010.

104. Chanzanagh HE, Akbar P, Garjan EA. The disabled and their everyday life experiences in Iranian culture. Int J Soc Sci Human Stud. 2012;4 (1):175-184.

105. Carlsson M, Eriksson S. Age discrimination in hiring decisions: evidence from a field experiment in the labor market. Labour Econ. 2019;59:173-183. doi:10.1016/j.labeco.2019.03.002

106. Andriessen I, Nievers E, Dagevos J, Faulk L. Ethnic discrimination in the Dutch labor market: its relationship with job characteristics and multiple group membership. Work Occup. 2012;39(3):237-269. doi:10.1177/0730888412444783

107. Shaw LR, Chan F, McMahon BT. Intersectionality and disability harassment: the interactive effects of disability, race, age, and gender. Rehabil Couns Bull. 2012;55(2):82-91. doi:10.1177/0034355211431167

108. Maroto M, Pettinicchio D, Patterson AC. Hierarchies of categorical disadvantage: economic insecurity at the intersection of disability, gender, and race. Gender Soc. 2019;33(1):64-93. doi:10.1177/0891243218794648

109. Gustavsen S, Olsson A, Søndergaard HB, et al. The association of selected multiple sclerosis symptoms with disability and quality of life: a large Danish self-report survey. BMC Neurol. 2021;21(1). doi:10.1186/s12883-021-02344-z

110. Hellem I, Førland G, Eide K, Ytrehus S. Addressing uncertainty and stigma in social relations related to hidden dysfunctions following acquired brain injury. Scand J Disabil Res. 2018;20(1):152-161. doi:10.16993/sjdr.24

111. Lohne V, Aasgaard T, Caspari S, Slettebø A, Nåden D. The lonely battle for dignity: individuals struggling with multiple sclerosis. Nurs Ethics. 2010;17(3):301-311. doi:10.1177/0969733010361439

112. Messmer Uccelli M, Specchia C, Battaglia MA, Miller DM. Factors that influence the employment status of people with multiple sclerosis: a multi-national study. J Neurol. 2009;256(12):1989-1996. doi:10.1007/s00415-009-5225-0

113. Roessler RT, Dent Gitchel W. Severity, employment, and gender: factors influencing Independence for adults with multiple sclerosis. $J$ Rehabil. 2013;79(4):33-45.

114. Reed KS, Meade M, Jarnecke M, Rumrill P, Krause JS. Disclosing disability in the employment setting: perspectives from workers with multiple sclerosis. J Vocat Rehabil. 2017;47(2):175-184. doi:10.3233/JVR-170893

115. Sweetland J, Riazi A, Cano SJ, et al. Vocational rehabilitation services for people with multiple sclerosis: what patients want from clinicians and employers. Multiple Sclerosis. 2007;13(9):1183-1189. doi:10.1177/1352458507078414

116. Shakespeare T. Disability Rights and Wrongs Revisited. Second ed. Hoboken: Taylor and Francis; 2013.

117. Peuravaara K. Reflections on collaborative research: to what extent and on whose terms? Scand J Disabil Res. 2015;17:272-283. doi:10.1080/ 15017419.2013 .859178

\section{Publish your work in this journal}

The Journal of Multidisciplinary Healthcare is an international, peer-reviewed open-access journal that aims to represent and publish research in healthcare areas delivered by practitioners of different disciplines. This includes studies and reviews conducted by multidisciplinary teams as well as research which evaluates the results or conduct of such teams or healthcare processes in general. The journal covers a very wide range of areas and welcomes submissions from practitioners at all levels, from all over the world. The manuscript management system is completely online and includes a very quick and fair peer-review system. Visit http://www.dovepress.com/testimonials.php to read real quotes from published authors.

Submit your manuscript here: https://www.dovepress.com/journal-of-inflammation-research-journal 